\title{
Primary cutaneous Ewing sarcoma - Case report
}

Jayme de Oliveira Filho ${ }^{1}$

Anna Rita Ferrante Mitidieri de Oliveira ${ }^{1}$

Natalie Haddad ${ }^{1}$

\author{
Ana Carolina Franco Tebet ${ }^{1}$ \\ Kassila Nasser ${ }^{1}$
}

\begin{abstract}
Ewing sarcoma is a primitive neuroectodermal tumor rarely occurs in the skin and sobcutaneous tissues. Generally Ewing's sarcoma is a primary bone tumor, but when present in soft tissues it characterizes an extremely uncommon clinical picture. It usually involves the deep subcutaneous tissue or muscles, and more rarely occurs like a primary skin cancer. Most patients are white, women, and in the second decade of life. The clinical features are a superficial mass, in average measuring $2-3 \mathrm{~cm}$, of soft consistency, freely mobile and sometimes painful. The more affected locations are upper and lower extremities, trunk, head, neck or multiple lesions. The presence of metastases is very rare.
\end{abstract}

Keywords: Dermatology; Diagnosis; Medical oncology; Pathology; Sarcoma, Ewing

\section{INTRODUCTION}

The extraosseous Ewing sarcoma is a neuroectodermal tumor of clear cells and very rare, with few cases reported in the literature. ${ }^{1,2}$

It is a primarily osseous tumoral lesion, and when present in soft tissues, it characterizes an extremely uncommon clinical picture. It usually involves the deep subcutaneous tissue or muscles, and more rarely occurs as primary skin cancer. ${ }^{1,2,3}$

Up to 2001, there were only 78 cases described in the literature; the majority of patients are white, women (2:1) and in the second decade of life (average age of $16 / 17$ years). ${ }^{1,3-5}$

The clinical picture is usually composed of a superficial tumoral mass of $2-3 \mathrm{~cm}$, of soft consistency, mobile, sometimes painful. The tumor is located in the middle dermis, deep dermis or superficial subcutaneous tissue and may involve the dermal papilla, with pedunculated tumoral presentation. The average evolution time to complement the diagnosis is 5 months. The more frequently affected locations are the upper and lower extremities, trunk, head and neck or even multiple lesions. . $^{1,3,-7}$

The presence of metastases is very rare, with only three cases described in the literature (one with local positive lymph nodes and two with metastatic disease, one in the stomach and the other with no location described), and two died. In the reviewed reports, the majority of the patients did not present evidence of metastatic disease during minimum 16year follow-up.

The diagnosis is done with aspiration cytology, immunohistochemistry, cytogenetics and molecular genetics of translocations. ${ }^{8,9}$ The Ewing sarcomas are formed by cells, most of which express the CD99 and are characterized by specific chromosomal translocation involving gene EWSR1 in chromosome 22q12, with an erythroblastosis virus-transforming gene, resulting in the oncogene fusion. ${ }^{4}$ Histologically, Ewing sarcoma is formed by small cells with round hyperchromatic nuclei and a single nucleolus. The cytoplasm is poorly defined, scarce, of clear coloration and with irregular vacuoles resulting from intracellular deposits of glycogen. ${ }^{79}$ Imaging exams are not clarifying enough for diagnosis but are helpful. ${ }^{9,10}$

Differential diagnosis is done with other neoplasms composed of small round cells, both primary neoplasms and cutaneous metastases. Primary neoplasms may be: Merkel cell carcinoma, eccrine spiradenoma, lymphomas, clear cell sarcoma, rhabdomyosarcoma, malignant rhabdoid tumor, malignant primitive neuroectodermal tumor, myoepithelial carcinoma, angiomatoid fibrous histiocytoma, poorly differentiated adnexal tumors and granulocytic sarcoma. Cutaneous metastases may derive from: osseous

Received on 18.06.2013.

Approved by the Advisory Board and accepted for publication on 17.08.2013.

Work performed at Medical School of Universidade de Santo Amaro (UNISA) - Santo Amaro (SP), Brazil.

Financial Support: None

Conflict of Interests: None.

Universidade de Santo Amaro (UNISA) - Santo Amaro (SP), Brazil 
Ewing sarcoma, large cell neuroendocrine carcinoma, small cell lung carcinoma and neuroblastoma. ${ }^{3,6,9,10}$

The treatment is initially done with surgical resection, being associated or not with chemotherapy and/or radiotherapy, depending on the size and location of the tumor. Radiotherapy is used when there are still positive margins after surgical resection. ${ }^{1,5,6}$

The cutaneous disease presents a slow course and an apparently favorable prognosis, with a survival rate of $91 \%$ in ten years, when compared to osseous or soft tissue Ewing sarcoma, which have worse prognosis. The less aggressive character of the cutaneous clinical picture probably occurs due to superficial location, smaller tumors and of easy access, allowing the detection both through routine clinical exam or by the own patient, early diagnosis and complete surgical resection, avoiding the onset of metastases. ${ }^{1,4,5,10}$

\section{CASE REPORT}

Female, 26 year-old, mixed race, with a complaint of tumoral lesion in the right clavicular region for 6 months.

At the exam, she presented tumoral lesion bulging over the cutaneous tissue, without compromising it, measuring $3 \times 4 \mathrm{~cm}$, soft, badly defined to palpation, painless, non-adhered (Figures 1 and 2).

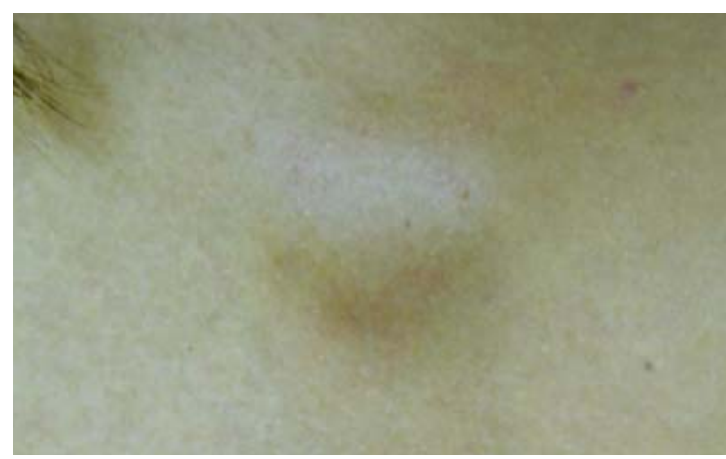

FIGURE 1: Tumoral lesion in right clavicular region

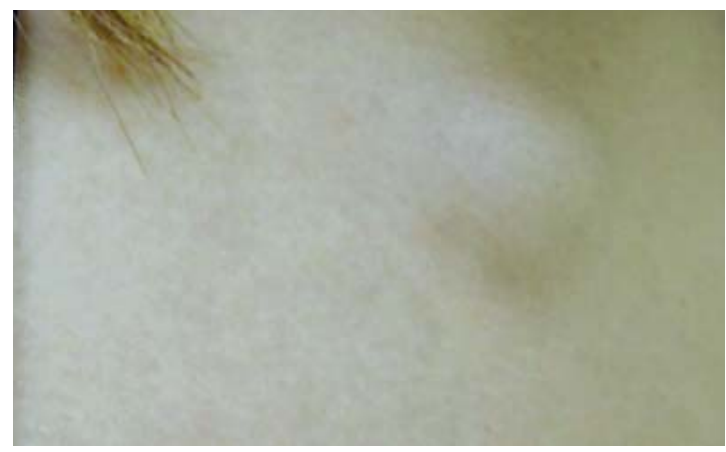

FIGURE 2: Tumoral lesion in right clavicular region
We performed the diagnostic hypothesis of lipoma and requested preoperative routine exams and USG.

We received exams with no alterations and imaging exam suspecting it to be lipoma.

During the intraoperative period, a tissue with bloody secretion was observed, of softened and friable consistency, whitish coloration, not encapsulated and non-adhered. In face of this atypical aspect for lipoma hypothesis, we forwarded the material to pathology, where immature neoplasia was observed, with round cell proliferation with large cytoplasm and nuclei with dense chromatin forming mantles, compatible with malignant neoplasia of round cells, requiring immunohistochemistry for differentiation, a technique that revealed CD99 + strong and diffuse, desmin + in isolated foci, EMA + in several foci, multiple enolase + foci, vimentin +, Ki67 + in 10\% of neoplastic cells and S100 protein + in multiple foci, where the diagnosis of Ewing sarcoma of soft parts was completed, with moderate level of proliferation (Figures 3, 4 and 5).

Thus the patient was referred to the oncology service where she is receiving chemotherapy.

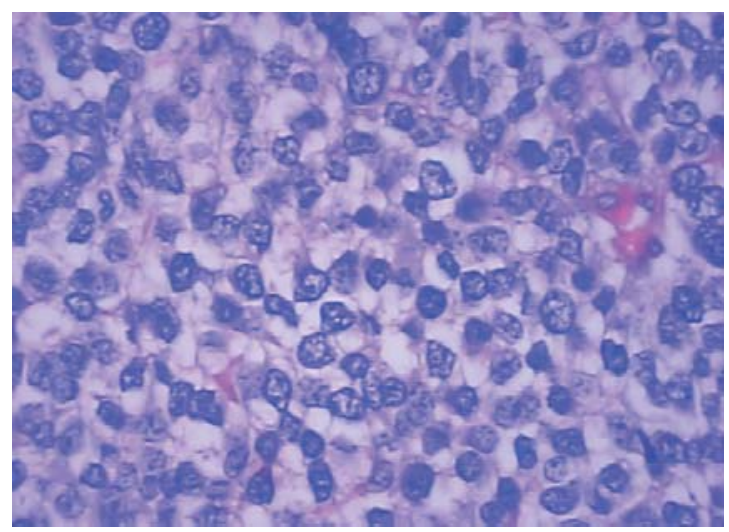

FIGURE 3: Glass slide stained with HE, 400x magnification, showing diffuse proliferation of cells with indistinct cytoplasm and small basophilic nuclei

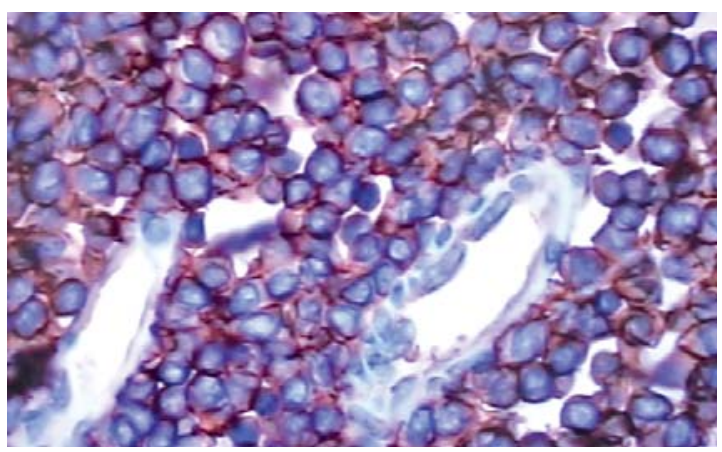

FIGURE 4: Immunohistochemistry strongly positive for CD99 


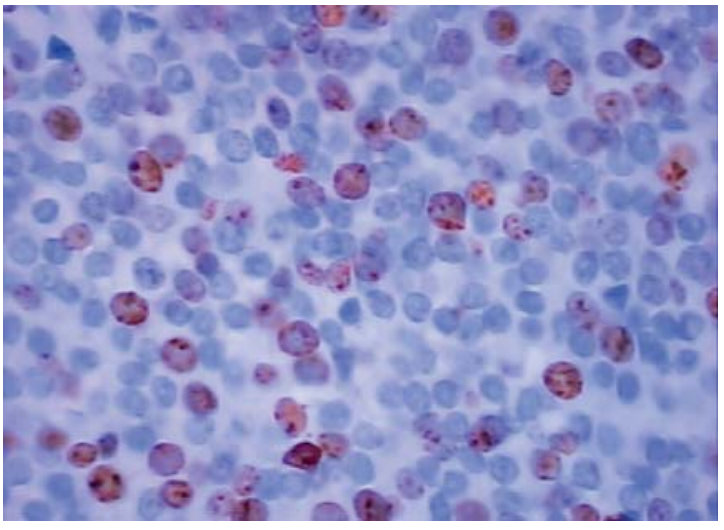

FigURE 5: Immunohistochemistry strongly positive for Ki67

\section{DISCUSSION}

The reported case increases the small index of described Ewing Sarcoma of soft parts, being in accordance with the greater incidence in women, although in a mixed race patient (it is more common in white women) and above the normally described age group. Lesion evolution was compatible with time and size described.
Normally, cutaneous tumors are considered of better prognosis when compared to the soft part ones, specially due to the possibility of early diagnosis. However, we believe that our patient was benefited due to the lesion location, which even being of the soft parts kind, was superficially located, making clinical observation easier.

Due to its rarity and morphological similarity to other cutaneous tumors, cutaneous Ewing sarcoma is subject to being clinically and pathologically subdiagnosed. Therefore, all should refer to this entity as a differential diagnosis, even in simpler cases like lipomas, and every lesion submitted to excision should be sent to the pathologist, for diagnostic confirmation.

Besides having an important contraindication against aspirative techniques, due to the possibility of not diagnosing an aggressive disease, one cannot trust exclusively in clinical and imaging exams, for they are not $100 \%$ sensitive.

This report serves as proof one more time that diagnostic confirmation by the anatomopathologist is required in face of any nodule-tumoral lesion, even if it clinically presents benign characteristics.

\section{REFERENCES}

1. Chow E, Merchant TE, Pappo A, Jenkins JJ, Shah AB, Kun LE. Cutaneous and subcutaneous Ewing's sarcoma: an indolent disease. Int J Radiat Oncol Biol Phys. 2000;46:433-8.

2. Somers GR, Shago M, Zielenska M, Chan HS, Ngan BY. Primary subcutaneous primitive neuroectodermal tumor with aggressive behavior and an unusual karyotype: case report. Pediatr Dev Pathol. 2004;7:538-45.

3. Ehrig T, Billings SD, Fanburg-Smith JC. Superficial primitive neuroectodermal tumor/Ewing sarcoma (PN/ES): same tumor as deep PN/ES or new entity? Ann Diagn Pathol. 2007;11:153-9.

4. Delaplace M, Lhommet C, de Pinieux G, Vergier B, de Muret A, Machet L. Primary cutaneous Ewing sarcoma: a systematic review focused on treatment and outcome. Br J Dermatol. 2012;166:721-6.

5. Collier AB 3rd, Simpson L, Monteleone P. Cutaneous Ewing sarcoma: report of 2 cases and literature review of presentation, treatment, and outcome of 76 other reported cases. J Pediatr Hematol Oncol. 2011;33:631-4.

6. Shingde MV, Buckland M, Busam KJ, McCarthy SW, Wilmott J, Thompson JF, et al. Primary cutaneous Ewing sarcoma/primitive neuroectodermal tumour: a clinicopathological analysis of seven cases highlighting diagnostic pitfalls and the role of FISH testing in diagnosis. J Clin Pathol. 2009;62:915-9.

7. Lee CS, Southey MC, Slater H, Auldist AW, Chow CW, Venter DJ. Primary Cutaneous Ewing's Sarcoma/Peripheral Primitive Neuroectodermal Tumors in Childhood: A Molecular Cytogenetic, and Immunohistochemical Study. Diagn Mol Pathol. 1995;4:174-81.

8. Hanaoka N, Goto T, Kasai T, Matsuura T, Nishisho T, Enishi T, et al. Extraskeletal Ewing's sarcoma in a 67-year-old man. J Orthop Sci. 2011;16:250-2.

9. Bahk WJ, Chang ED, Bae JM, Chun KA, Lee AH, Rho SY, et al. Primary cutaneous Ewing's sarcoma/primitive neuroectodermal tumor manifesting numerous small and huge ulcerated masses: its complete remission by chemotherapy and magnetic resonance imaging findings. Skeletal Radiol. 2010;39:595-600.

10. Machado I, Llombart B, Calabuig-Fariñas S, Llombart-Bosch A. Superficial Ewing's sarcoma family of tumors: a clinicopathological study with differential diagnoses. J Cutan Pathol. 2011;38:636-43.

\author{
MAILING ADDRESS: \\ Anna Rita Ferrante Mitidieri de Oliveira \\ Rua Professor Enéas Siqueira Neto, 340 \\ Jardim das Imbuias \\ 04829-300 - São Paulo - SP \\ Brazil \\ E-mail:annarita.fmo@gmail.com
}

How to cite this article: Oliveira Filho J, Tebet ACF, Oliveira ARFM, Nasser K, Haddad N. Primary cutaneous Ewing sarcoma - Case report. An Bras Dermatol. 2014;89(3):501-3. 